\title{
Circuncisão masculina e infecção pelo HIV: uma polêmica mundial sem voz brasileira
}

\author{
Male circumcision and HIV infection: an international \\ debate with no Brazilian participation
}

Euclides Ayres de Castilho ${ }^{1}$ e Mark Drew Crosland Guimarães $\quad{ }^{2}$

\section{RESUMO}

Os autores trazem para reflexão a questão da circuncisão masculina como fator de proteção para infecção pelo HIV. Em breve bistórico da abordagem do problema, na literatura mundial, identificam a ausência de pesquisas brasileiras sobre o tema. Por fim, problematizam a situação, lembrando que circuncisão masculina autodeclarada é passível de erros de classificação de relevante magnitude, implicando, por isso, vícios nas estimativas de riscos.

Palavras-chaves: Circuncisão masculina. Transmissão heterossexual do HIV. Erros de classificação. Brasil.

\section{ABSTRACT}

The authors discuss male circumcision as a protective factor against HIV transmission. The absence is noted of Brazilian data published in the international literature regarding this issue. Finally, it is emphasized that self-declared circumcision status is subject to substantial misclassification with the generation of biased risk estimates.

Key-words: Male circumcision. HIV heterosexual transmission. Misclassification errors. Brazil

Inúmeros trabalhos sobre circuncisão masculina e fatores de risco para a transmissão heterossexual do HIV foram apresentados no penúltimo Congresso Internacional de AIDS, realizado em Durban, 2000. Certamente, esta foi uma das razões que levaram os organizadores do XIV Congresso Internacional (Barcelona, 2002) a incluírem heterosexual transmission, circumcision - como palavra-chave para a disposição dos trabalhos epidemiológicos a serem apresentados.

A questão da não-circuncisão como fator de risco para a infecção pelo HIV foi trazida, pela primeira vez, para a literatura médica, em 1988, por Simonsen e colaboradores ${ }^{13}$, apresentando uma investigação sobre fatores de riscos para a transmissão heterossexual do HIV, conduzida, em Nairobi, entre 340 homens, pacientes de uma clínica especializada em infecções sexualmente transmissíveis. Os homens sem circuncisão tiveram freqüência maior de soropositividade para o HIV, comparados com aqueles circundados (19,5\% versus 8,3\%; OR=2,7; I 95\% C de 1,3 a 5,4). 0 mesmo grupo de Autores ${ }^{3}$ estudando, naquela cidade, uma coorte de 370 homens, inicialmente sem infecção pelo HIV, encontrou, por meio de uma análise de regressão logística, que o risco para soro-conversão estava independentemente associado com o fato do indivíduo ser circundado (RR de 8,2 e I 95\% C de 3 a 23).
Em 1999, Halperin e Bailey ${ }^{9}$, em estudo ecológico, mostraram que as taxas estimadas de soroprevalência para o HIV, em países africanos, eram inversamente proporcionais às freqüências estimadas de homens circundados. Esses Autores, na época, sugeriram, fortemente, que a comunidade internacional de saúde oferecesse condições para realização de postectomia nos serviços de assistência médica, como medida de prevenção da transmissão do HIV por contato heterossexual. Por sinal, esse artigo suscitou o envio de várias correspondências para a revista The Lancet, onde ele foi publicado (vide, por exemplo, o volume 355, número 9.207, do ano de 2000). Assim, restrições foram feitas ao desenho de estudo, que por ser do tipo ecológico, poderia estar implicando falácias ecológicas; além delas, o fato dos países da Europa Ocidental, com baixa freqüência de homens circundados e níveis mundiais de menor magnitude de infecção pelo HIV quando cotejados com os Estados Unidos (com alta prevalência de HIV/AIDS e onde a circuncisão masculina é comum) não suportar essa hipótese, também foi levantado. Vale lembrar que Halperin recebeu severas críticas por ter dito a um jornal da imprensa californiana: "If I were a top [insertive partner in anal intercourse], and I didn't like to use condoms, I would consider getting circumcised".

\footnotetext{
1. Departamento de Medicina Preventiva da Faculdade de Medicina da Universidade de São Paulo, São Paulo, SP. 2 Departamento de Medicina Preventiva e Social da Faculdade de Medicina da Universidade Federal de Minas Gerais, Belo Horizonte, MG.

Endereço para correspondência : Prof. Euclides Ayres Castilho. Av. Dr. Arnaldo 455, 01246-903 São Paulo, SP.

e-mail: castil@usp.br

Recebido para publicação em 30/9/2003

Aceito em 9/10/2003
} 
Seus julgadores discordavam do caráter absoluto da afirmação e do seu apelo para uma mídia, geralmente, sensacionalista. Além disso, até então, a circuncisão como fator de proteção para a infecção pelo HIV, era resultado de estudos empíricos, desenvolvidos entre homens com práticas predominantemente heterossexuais, e residentes na África subsaareana.

Em 2000, o periódico AIDS contempla um artigo de revisão sistemática e meta-análise sobre esse assunto ${ }^{14}$. De 27 estudos incluídos, 21 mostraram um risco reduzido de infecção pelo HIV em homens circundados. Vale dizer que todos os estudos diziam respeito a países africanos.

Outrossim, é oportuno salientar que a relação entre circuncisão e risco para infecção pelo HIV é raramente examinada em homens queforem sexocom outroshomens. Um estudo estadunidense ${ }^{10}$, do tipo transversal, encontrou que homossexuais não-circundados tinham o dobro da chance de ser HIV positivo, comparados com os circundados, mas com um intervalo de $95 \%$ de confiança, tendo o valor 1 como limite inferior. Esse suposto excesso de risco, por outro lado, não foi observado em uma investigação ${ }^{1}$ feita em Sydney, Austrália, onde 63 homens, recém-infectados pelo HIV e referindo coito anal desprotegido como sendo suas práticas de maior risco para o HIV, não apresentaram diferenciais no que tange ao status de circundado, tanto entre aqueles com práticas de sexo anal predominantemente insertivas e os com práticas de sexo anal predominantemente receptivas.

Longe da pretensão de sermos autênticas vozes brasileiras no debate, mas por razões a seguir descritas, remetemos este artigo de opinião.

1) Buscando artigos científicos na base-de-dados MEDLINE por meio das palavras-chave "HIV and male circumcision and brazil", nenhum trabalho foi encontrado; 2) não recordamos de matérias na imprensa brasileira sobre esse debate; 3) na condição de pesquisadores responsáveis por uma investigação sobre fatores associados à transmissão heterossexual do HIV de homens infectados para suas parceiras sexuais, achamos oportuno apresentar nossos resultados, referentes à transmissão sexual no sentido homemmulher. Detalhes da metodologia e resultados da investigação foram publicados alhures ${ }^{478}$. Dentre 377 pares, das 180 mulheres infectadas, $85 \%$ eram parceiras de circundados, sendo essa proporção de $86 \%$, nas mulheres negativas para o HIV. Esta pequena diferença não é estatisticamente significante (qui-quadrado $=0,128$; $\mathrm{p}=0,720)$. Encontramos os seguintes fatores independentemente associados com a transmissão do HIV tipo homem-mulher: a) prática de sexo anal; b) não-uso ou uso irregular de preservativo nas relações sexuais vaginais; c) número de relações sexuais, no ano anterior à data da entrevista; d) uso de contraceptivo oral; e) sangramento vaginal pós-coito; f) e uma forte interação entre sangramento vaginal e história prévia de infecções sexualmente transmitidas; 4) colocamos ou apresentamos pomos para reflexão a nossa preocupação com o fato das análises sobre circuncisão masculina como fator de proteção para a infecção pelo HIV não levarem em consideração que circuncisão auto-referida quando comparada com o status dado por exame médico tem baixa concordância, daí derivando erros de classificação que, por seu turno, levam a estimativas viciadas dos riscos associados. Já, em 1958, Lilienfelde Graham ${ }^{11}$ insistiam na frequiência de 34,4\% de discordância entre a afirmação de paciente sobre sua condição de circuncidado e os achados médicos. Em um livro clássico de epidemiologia ${ }^{12}$, a questão é reavaliada a partir dos dados de Dunn e Buell ${ }^{5}$. Os Autores ${ }^{12}$ do texto, cotejando as informações de 166 pacientes sobre seus status em relação à circuncisão com os achados médicos, observaram $28 \%$ de falsospositivos e 17\% de falsos-negativos, indicando, desta maneira, que os erros de classificação ocorrem nos dois sentidos. Para estes dados, encontramos um índice kappa de concordância $=0,462$, longe do ideal, isto é, igual a 1; 5) finalmente, propomos a professores de epidemiologia submeterem a seus alunos o seguinte exercício: recalcular os riscos observados nos estudos sobre associação entre circuncisão e infecção pelo HIV, ajustados aos erros de classificação.

\section{REFERÊNCIAS BIBLIOGRÁFICAS}

1. Andrew EG, Hendry 0, Clark E, Kippax S, Kaldor JM. Circumcision and male-tomale sexual transmission of HIV. AIDS 15:1188-1189, 2001.

2. Caceres CF, van-Griensven GJP. Male homosexual transmission of HIV-1. AIDS 8:1051-1061, 1994.

3. Cameron DW, D'Costa LJ, Maitha GM, Cheang M, Piot P, Simonsen JN, Ronald AR, Gakinya MN, Ndinya-Achola J0, Brunham RC, Plummer FA. Female to male transmission of Human Immunodeficiency Virus type 1: risk factors for seroconversion in men. Lancet 2:403-407, 1989.

4. Castilho EA, Boschi-Pinto C, Guimarães MDC. Male circumcision and HIV heterosexual transmission. In: Resumos da XIV International AIDS Conference, Barcelona, CD-ROM, 2002.

5. Dunn Junior JE, Buell P. Association of cervical cancer with circumcision of sexual partner. Journal of National Cancer Institute 22:749-764, 1959.

6. Guimarães MDC, Muñoz A, Boschi-Pinto C, Castilho EA. HIV infection among female partners of seropositive men in Brazil. American Journal of Epidemiology 142:538-547, 1995.

7. Guimarães MDC, Vlahov D, Castilho EA. Postcoital vaginal bleeding as a risk factor for transmission of the Human Immunodeficiency Virus in a heterosexual partner study in Brazil. Archives of Internal Medicine 157:1362-1368, 1997.

8. Guimarães MDC, Boschi-Pinto C, Castilho EA. Safe sexual behaviour among female partners of HIV-infected men in Rio de Janeiro, Brazil. International Journal of STD \& AIDS 12:334-341, 2001.

9. Halperin DT, Bailey RC. Male circumcision and HIV infection. Lancet 354:1813$1815,1999$.

10. Kreiss JK, Hopkins SG. The association between circumcision status and HIV infection among homosexual men. Journal of Infectious Diseases 168:1404-1408, 1993.

11. Lilienfeld AM, Graham S. Validity of determining circumcision status by questionnaire as related to epidemiological studies of cancer of the cervix. Journal of the National Cancer Institute 21:713-720, 1958.

12. MacMahon B, Pugh TF. Epidemiology: principles and methods. Little, Brown and Company, Boston, 1970.

13. Simonsen JN, Cameron DW, Gakinya MN, Ndinya-Achola JO, D'Costa LJ, Karasira P, Cheang M, Ronald AR, Piot P, Plummer FA. Human Immunodeficiency Virus infection among men with sexually transmitted diseases. The New England Journal of Medicine 319:274-278, 1988.

14. Weiss HA, Quigley MA, Haynes RJ. Male circumcision and risk of HIV infection in sub-Saharan Africa: a systematic review and meta-analysis. AIDS 14:23612370,2000 . 